\title{
Sessenta anos de televisão sob a ótica de especialistas ${ }^{1}$
} Sixty years of television under the optics of specialists

\section{Fernando Mariano de Siqueira}

Professor nas áreas de Fotografia e TV da Faculdade Paulus de Tecnologia e Comunicação Fapcom de São Paulo; mestrando do Programa de Comunicação da Universidade Municipal de São Caetano do Sul - USCS; diretor e produtor de programas para TV aberta e Internet, tendo desenvolvido também emissoras de TV on-line.

A história da Televisão no Brasil: do início aos dias de hoje, livro da Editora Contexto organizado por Ana Paula Goulart Ribeiro, Igor Sacramento e Marco Roxo, foi lançado em 2010, tem 347 páginas e analisa diferentes aspectos dos principais momentos da televisão no Brasil.

O livro é divido em seis capítulos, cada um referente a uma década de história, sendo que cada capítulo é composto de dois ou três artigos. Cada artigo trata de um programa, momento ou período importante de cada período, de modo que a obra, segundo os organizadores, propõe um estudo amplo sobre a televisão.

\section{Anos 1950 - a televisão em formação}

No artigo "Imaginação televisual e os primórdios da TV no Brasil", a jornalista e pesquisadora Marialva Carlos Barbosa analisou o período pré-televisão e sua implantação a partir de 1950. Na análise, a referida autora trabalhou a chegada da televisão por intermédio de mensagens publicitárias e matérias jornalísticas publicadas nas décadas de 1940 e 1950, e analisou a "aura" de sonhos, utopias e modernidade que estava associada ao novo meio.

O artigo "As primeiras produções teleficcionais", de Cristina Brandão, aborda a criação de uma linguagem própria de ficção para o novo meio, motivada pela iniciativa dos profissionais pioneiros. Em um período marcado pelo amadorismo empresarial, a autora mencionada analisou a criação do "teleteatro" (apresentações de história com começo, meio e fim no mesmo episódio) e da telenovela (gênero que acabou ganhando importância, motivando o crescimento da mídia e levando o teleteatro à extinção na década seguinte).
O capítulo seguinte é dedicado à década de 1960, na qual a TV entra em franca expansão e assume o papel de principal mídia para a sociedade brasileira.

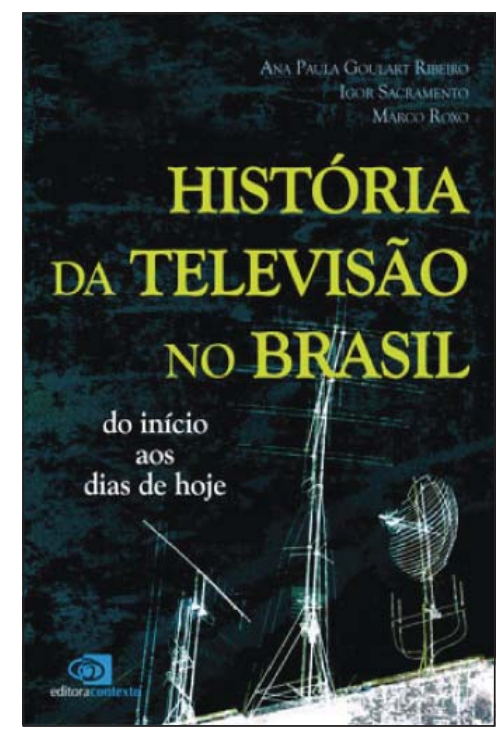

Alexandre Bergamo assinou o primeiro artigo deste capítulo: "A reconfiguração do público". O surgimento da TV Excelsior (1960) e da TV Globo (1965), ambas com visão empresarial, a organização da grade de programação em faixas etárias e o surgimento da programação vertical (divisão da grade em horários, de acordo com o público, mantendo uma sequência racional entre o público dos programas) e horizontal (programas que iam ao ar todos os dias, rigorosamente no mesmo horário, como forma de criar o hábito de assistir a tais programas) tornam a TV um veículo próprio, não mais um simples derivado do rádio.

A TV tornava-se a principal fonte de lazer noturno e familiar. Os ídolos do rádio migraram para a TV. Surgiram, nessa década, os programas populares, a pesquisa de audiência passou a ser utilizada pela televisão e o preconceito aos meios eletrônicos (rádio e TV) ganhou força: consideradas mídias populares, passou a existir a diferenciação entre profissionais de teatro (com status superior) e profissionais de rádio e TV (em especial atores, considerados profissionais de segunda categoria).

"A MPB na era da TV", artigo de Marcos Napolitano, analisa a transformação da programação televisiva, fechada até então em teleteatros, programas de perguntas e respos-

\footnotetext{
${ }^{1}$ Ribeiro, Ana Paula Goulart; Sacramento, Igor; Roxo, Marco (orgs.). A história da TV no Brasil: do início aos dias de hoje. São Paulo: Contexto, 2010. 347p.
} 
tas, entrevistas e shows de variedades, ao implantar a transmissão de apresentações musicais e festivais. Neste aspecto, a TV Record, de São Paulo, foi a emissora que iniciou a mudança, ao misturar em sua programação os artistas de carreira já consolidada (considerados de "velhaguarda") e os artistas surgidos pós-bossa nova (considerados, naquele momento, como os ícones da música jovem). Seus programas musicais - em conjunto com o movimento político pós-1964 e a participação dos jovens neste período - incentivaram o surgimento de novos artistas e movimentos musicais, acirrando a disputa entre estes movimentos (com destaque para os festivais, que se tornaram ícones daquele período).

\section{Anos 1970 - a TV em ritmo de modernização}

Trata-se do terceiro capítulo do livro. Os pesquisadores Ana Paula Goulart Ribeiro e Igor Sacramento, que ao lado de Marco Roxo assinaram a organização do livro, analisaram a "Renovação estética da TV". Se a década de 1960 foi marcada pela popularização do meio, a década seguinte seria marcada pela extinção do popular e o crescimento de uma programação elaborada e em rede nacional. Nesse movimento, a Rede Globo tornou-se líder de audiência e criou um padrão próprio de qualidade, investindo em programas e em estratégias de planejamento e produção. Essas estratégias de modernização, segundos os autores, eram incentivadas pelo governo da época, que via na televisão uma forma de mostrar a modernização do Brasil.

O artigo seguinte, ainda no capítulo sobre a década de 1970, é “O programa 'Abertura' e a épica de Glauber Rocha", de autoria de Regina Mota, que trata do programa "Abertura" (Rede Tupi, 1979-1980), o qual marcou o retorno do diretor Fernando Barbosa Lima à TV, após um autoexílio de cerca de dez anos (motivado pela instauração do Ato Institucional n. 5 - Al-5) e da estreia do cineasta Glauber Rocha também nesse meio. A autora abordou as polêmicas quanto à presença do povo e do popular e a busca de uma valorização da cultura genuinamente brasileira, que foram marcas do trabalho de Glauber no "Abertura", considerado pela autora como seu testamento estético e político.

\section{Anos 1980 - a televisão em transição democrática}

Nos capítulos sobre os anos de 1980 e 1990, são três os artigos que analisam a década, ao contrário dos demais capítulos, compostos de dois artigos por década.

Em "O moderno e o popular na TV de Silvio Santos", a pesquisadora Maria Celeste Mira analisou o surgimento do SBT, criado a partir do programa dominical de seu dono
(Silvio Santos, no ar desde 1962), e sua opção por uma programação popular que começara a ser extinta no final da década de 1960. Com esses programas, a emissora logo conseguiu uma boa fatia de audiência, mas muito pouco retorno comercial. Em seus dois primeiros anos de existência, foi rotulada de popularesca. Esse rótulo e o baixo retorno comercial forçaram a uma modernização do SBT, com a extinção de alguns programas e o investimento em outros, de melhor qualidade. Porém, devido aos conteúdos dos programas (com melhor acabamento estético e linguagem moderna, porém ainda de conteúdo popular), a emissora passou a ser vista pelos críticos como "brega". Cabe à emissora também o mérito de ter dado novo rumo aos programas de auditório, forçando a Rede Globo a investir novamente nesse tipo de produção televisiva.

Marco Roxo assinou o artigo "A volta do jornalismo cão na TV". O "Aqui agora", do SBT, é analisado a partir do "Aqui e agora" da TV Tupi (1979-1980) - também citado no artigo de Maria Celeste Mira. O telejornal inovou com a técnica da câmera em movimento e com o repórter participando da ação, narrando-a sempre em tempo presente e, também, usou de matérias em perseguições policiais e assuntos considerados sensacionalistas.

"A teledramaturgia juvenil brasileira", de Marina Caminha, fecha o capítulo destinado aos anos de 1980. A partir dos elementos narrativos da dramaturgia voltada ao público jovem, a realidade político-social e os processos sociais da época, a autora analisou essas produções do período, com especial destaque ao humor, às novelas e ao seriado "Armação ilimitada". As obras analisadas pela autora como características da década fazem referência à arte pop, à pós-modernidade, ao crescimento do consumo, aos produtos eletrônicos e, principalmente, à paródia do meio (TV) ou da sociedade.

\section{Anos 1990 - a televisão em divergência}

Neste capítulo, também divido em três artigos, tem-se no primeiro a autoria de Valério Cruz Britos e Denis Gerson Simões, sob o título "A reconfiguração do mercado de televisão pré-digitalização". A partir de transformações sociais e políticas das décadas de 1980 e 1990, a televisão foi analisada sob as perspectivas das transformações, adaptações e inovações. Foi a década de implantação da TV por assinatura no Brasil que fez parte da audiência dos canais abertos (em especial, das classes sociais A e B) migrar para a nova modalidade de TV. Nesta década, houve o retorno da programação popular, usada como estratégia para atender ao público das classes $C$ e $D$, que tinham, nesse momento, a possibilidade de ter um aparelho de TV. Essa nova configuração de público e sua predile- 
ção pela programação popular motivou a gradual queda de audiência da Rede Globo e uma maior concorrência entre as emissoras. Na TV por assinatura em especial e em partes pela TV aberta, foi a década da importação de programas que atingiu um índice expressivo (como novelas mexicanas e documentários norte-americanos).

A novela "Pantanal" e as novas formas de ficção televisiva constituem o assunto do artigo seguinte, de Beatriz Becker. A novela produzida pela extinta Rede Manchete, em 1990, inovou ao adotar elementos estéticos presentes no cinema (e praticamente proibidos na televisão), como o plano geral (imagem aberta do ambiente), o silêncio, cenas longas e contemplativas da paisagem natural. Seu êxito de audiência mobilizou uma reação da Rede Globo e das demais emissoras, a ponto de modificar também o telejornalismo (como estratégia para fidelizar a audiência). Segundo a autora, "Pantanal" servia como redenção de um mundo calmo e distante ainda alcançável.

O capítulo sobre os anos de 1990 encerra-se com uma análise do jornalístico híbrido, que se utilizou de elementos ficcionais. É o caso do programa "Linha direta" que, apesar do conteúdo policial, era considerado pela Rede Globo como programa de utilidade pública. O artigo assinado por Kleber Mendonça analisa as características do programa que unia a linguagem da telenovela com assuntos populares, junção que levou o programa a ter grande audiência e tornar-se objeto de investigação de outros estudiosos (como Martín-Barbero, Muniz Sodré e Mikhail Bakhtin) sobre o sensacionalismo e a literatura popular.

\section{Anos 2000 - a televisão em convergência}

O último capítulo do livro começa com o artigo "Cinema e televisão no contexto da transmediação", de Yvana Fechine e Alexandre Figueirôa, que analisa a digitalização dos meios de produção (câmeras, ilhas de edição, outros equipamentos), a digitalização da exibição e da disponibilização dos conteúdos audiovisuais (como o DVD, o blu-ray e a transmissão via Internet), e a integração destes produtos à Internet. Fechine \& Figueirôa também estudaram a implantação da TV digital, suas propostas de interatividade e a programação em alta definição. Os referidos autores analisaram ainda a transmediação, em que uma narrativa ocorre "em múltiplas plataformas de mídia, manifestando-se em cada como um novo texto" (2010: 284). Além disso, no artigo, há análise da relação direta de filmes coproduzidos, financiados ou feitos em parceria de divulgação com emissoras de TV, com destaque às produções da Globo Filmes (dentre as quais, alguns filmes viraram minisséries e determinadas séries viraram filmes) e ao programa público de financiamento ao documentário DOCTV, ligado a emissoras públicas.
O último artigo do capítulo aborda "A ficção televisiva no mercado digital", de Ana Silvia Médola e Léo Vitor Redondo. Neste, foi analisada a comunicação pervasiva, ou seja, os processos de comunicação que se espalham nas mais diversas formas e dispositivos (sejam eles móveis, sejam fixos). Os autores estudaram as diferentes formas de interatividade atuais e analisaram a presença da interatividade via Internet, via telefone ou via mensagem de texto nas produções televisivas dos anos de 2006 e 2007.

\section{Considerações sobre a obra}

A iniciativa de uma obra relativa à história da TV sempre é valida, pois abre espaço para registrar a evolução do meio e das comunicações. Apesar de a obra trabalhar o assunto televisão de maneira consistente e coerente, desprovida das clássicas posições que caracterizam a TV como veículo superficial e manipulador, dois pequenos deslizes são cometidos.

O primeiro deles ocorreu no artigo de Valério Cruz Britos e Denis Gerson Simões, "A reconfiguração do mercado de televisão pré-digitalização", no qual os autores erraram ao citar alguns programas populares que surgiram nesta década (2010: 226), mesclando produções das redes Manchete e Bandeirantes ("Magdalena" e "Manchete verdade" eram um programa só, veiculado pela Rede Manchete sob o nome "Magdalena Manchete verdade", e "Tempo quente" era programa da Rede Bandeirantes), e se equivocaram em relação ao nome do jornal policial da CNT ("190 urgente"). Esses fatos não tiraram o crédito do artigo, mas criaram a possibilidade de uma informação incorreta tornar-se verdade acadêmica.

O segundo deslize apareceu no artigo "A ficção televisiva no mercado digital", no qual os autores preconceituosamente classificaram a publicação de notícias e sites por fãs de programas e séries como uma experiência amadora e até mesmo oportunista (2010: 324). Considerando-se a pouca importância que algumas emissoras dão aos seus produtos na Internet (como os próprios autores citaram a experiência da TV Cultura e da Rede Record, que ainda não entenderam que o site de produções estreita a relação com o público e perpetuam essas produções), é o trabalho de fãs que permite a expansão da memória dessas produções.

Em suma, trata-se de um livro no qual, apesar de o título sugerir uma obra cronológica e didática sobre o tema, com o decorrer dos capítulos, os leitores descobrem que ela não contempla fatos históricos importantes (como a falência das redes Excelsior, Tupi e Manchete).

Por sua vez, a coletânea cumpre seus objetivos e se coloca como nova opção à difusão da memória da televisão, permitindo que se vá além dos registros produzidos ape- 


\section{Sessenta anos de televisão sob a ótica de especialistas}

nas pela Rede Globo - a qual, até o momento, era a empresa que dava o devido valor para os registros da memória e da história da TV -, ao incentivar a publicação de livros e sites sobre sua própria história, elaborados por autores que participaram dessa mesma trajetória histórica ou por historiadores contratados pela emissora para a publicação destas obras.

Eis, portanto, um livro histórico sob o olhar de pesquisadores e estudiosos da televisão brasileira. 